\title{
A method of determining the thermal power demand of buildings connected to the district heating system with usage of heat accumulation
}

\author{
Michat Turski ${ }^{1, *}$, and Robert Sekret $^{1}$ \\ ${ }^{1}$ Faculty of Infrastructure and Environment, Czestochowa University of Technology, \\ ul. Brzeznicka 60A, 42-200 Czestochowa, Poland
}

\begin{abstract}
The paper presents a new method of determining the thermal power demand of buildings connected to the district heating system, which included the actual heat demand and the possibility of balancing the thermal power using the thermal storage capacity of district heating network and internal heat capacity of buildings. Moreover, the analysis of the effect of incidence of external air temperature and duration of episodes with the lowest outdoor temperatures on the thermal power demand of district heating system was conducted.
\end{abstract}

\section{Introduction}

One way to reduce pollution from dispersed sources of low power (i.e. low emission) can be a significant development of district heating systems. This is caused by the high efficiency of these systems and modern solutions for reducing pollution in sources in comparison to dispersed sources [1].

One of the barriers to the development of district heating systems is that the buildings connected to the district heating network are highly volatile of daily demand for thermal power, what causes problems when is designing power of heat sources in the district heating system. This occurs regardless of the generation of heat networks, or projected scenarios of their development [2-4]. In addition, pay special attention to the very rare cases of a value equal to or below the design temperature of the outside air during the heating season $[5,6]$. It can be concluded that the maximum design parameters of the heat source in heating networks are not being met [7]. The effect of oversized power of heat sources is a decline in the profitability of district heating systems [8]. Currently used methods of design power of heat sources of the district heating system based on the design temperature of the outside air. In addition, sources of heat are designed with more power due to the anticipated development of the buildings infrastructure and future demand for thermal power. However, this trend does not necessarily have to be maintained because of the intense thermal modernization of existing buildings and use new building technologies with extremely low heat consumption [9-11]. In the currently used calculation is not taken

\footnotetext{
*Corresponding author: m.turski@is.pcz.pl
} 
into account the thermal storage capacity of district heating network and internal heat capacity of buildings $[12,13]$.

In this material it is important to present a new calculation method and a new perspective on problem of current oversizing of heat sources capacities of district heating systems. New method includes the actual heat demand and the possibility of balancing the thermal power using the thermal storage capacity of district heating network and internal heat capacity of buildings.

\section{Method of determining the thermal power with usage of heat accumulation}

The proposed method consists of seven stages: analysis of the hourly frequency of outside air temperatures, analysis of average daily outside air temperature, analysis of frequency and duration of episodes with the lowest values of outside air temperature, determine the actual thermal power demand of buildings, analyse of the possibility of balancing the thermal power using the thermal storage capacity of district heating network, analyse of the possibility of balancing the thermal power using the internal heat capacity of buildings and determine the reduction in demand for thermal power of district heating system.

On the basis of climatic data for the considered area, designated as data for the standard meteorological year, should be determine the hourly frequency of the temperature in regulation range of the district heating network (e.g. from $-20^{\circ} \mathrm{C}$ to $12^{\circ} \mathrm{C}$ ) during the heating season (e.g. October-April).

Then should be analyzed the average daily temperature of the outside air. Such an analysis should be carried out on the basis of measurement data from the nearest meteorological station or data from weather monitoring of the system. Using the method of decomposition of the time series can be estimated distribution of the forecast external temperature for the coming years. Then, based on the obtained distribution of the value of the coefficient of determination $\mathrm{R}^{2}$ resulting from the number of seasons to be analyzed, select the forecast based on time series with the best fit.

It is likely that the analysis of the average daily temperature of the outside air using the method of decomposition of the time series will not be precise (coefficient of determination $\mathrm{R}^{2}<0.8$ ) [14-16]. For such a case it is necessary to carry out further analysis of frequency and duration of episodes with the lowest values of outside air temperature. This method involves the determination of a set of the average daily outside air temperature, from the period of possibly the greatest number of years ( $\mathrm{min}$. 30), episodes lasting from one to up to five days. The criterion for the designation of the episodes of time should be a temperature below the design temperature (e.g. in the range from $-15^{\circ} \mathrm{C}$ to $-20^{\circ} \mathrm{C}$ ). Temperature ranges should be divided as $1 \mathrm{~K}$.

If the value of the coefficient $\mathrm{R}^{2}$ are satisfactory, but the forecasted temperatures are still doubtful (e.g. are too high), it is also recommended to carry out this part of the analysis.

To determine the planned heating demand are required characteristics of district heating network. To their designation may be used of heating curves depending on outside air temperature. In that case, use heating curves of the network side (high performance), as well as heating curves on the installation side (low performance). Return temperatures of both the network and the installation are taken as the result of heat supply to end users. On this basis shall be designated predicted heat fluxes to meet the needs of end users, depending on the temperature of outside air. This method involved the use of the incidence of outside air temperature based on standard meteorological year. This determines the computing standard value of the planned thermal power demand by end users.

In addition to above can be practically used heat capacity of the heating network for the purpose of heat accumulation using increasing the temperature of the water network in 
supply, return or together. In the case of increasing the temperature of supply water the parameter limiting is the maximum operating temperature due to the recommended operating conditions of pre-insulated district heating pipes. It can be assumed that this temperature is up to $130-135^{\circ} \mathrm{C}$. The other two methods are not taken into account due to the increased cost of relief tubing or development of each substation. The amount of heat possible to accumulate in the district heating network, by increasing supply temperature can be calculated from equation (1):

$$
Q_{A, n}=V \rho c_{p} \Delta T 10^{-3}, M J
$$

where:

$Q_{A, n}$ - amount of heat possible to accumulate in the district heating network, by increasing supply temperature, $\mathrm{MJ}$,

$V$ - water volume of heating network at supply, $\mathrm{m}^{3}$,

$\rho$ - density of water, $\mathrm{kg} / \mathrm{m}^{3}$,

$c_{p}$ - specific heat capacity of water, $\mathrm{kJ} /(\mathrm{kg} \mathrm{K})$,

$\Delta T$ - temperature difference, $\mathrm{K}$.

Compensating time of heating source power reduction using a heat accumulation on the district heating supply can be calculated from the equation (2):

$$
\tau_{K, n}=Q_{A, n} /\left(3600 \Delta Q_{s r}\right), h
$$

where:

$\tau_{K, n}$ - compensating time of heating source power reduction using a heat accumulation on the district heating supply, h,

$Q_{A, n}$ - amount of heat accumulated in the heating network, MJ, $\Delta Q_{s r}$ - assumption in reduction of heat source power, MW.

Another possibility of using the heat accumulation give buildings connected to the district heating network. The accumulated amount of heat by using the internal heat capacity of buildings connected to the district heating network can be calculated from the equation (3):

$$
Q_{A, b}=C_{m} \Delta T_{b} 10^{-6}, M J
$$

where:

$Q_{A, b}$ - accumulated amount of heat by using internal heat capacity of buildings connected to district heating network, MJ,

$C_{m}$ - value of internal heat capacity of building, $\mathrm{J} / \mathrm{K}$,

$\Delta T_{b}$ - building internal temperature drop, $\mathrm{K}$.

The value of the internal heat capacity of buildings should be calculated for the total area of heated buildings considered using the equation (4):

$$
C_{m}=K_{j} A_{f} 10^{-6}, M J / K
$$

where:

$C_{m}$ - value of internal heat capacity of building, $\mathrm{MJ} / \mathrm{K}$,

$A_{f}$ - heated area, $\mathrm{m}^{2}$,

$K_{j}$ - internal heat capacity relative to the surface area of the building element, $\mathrm{J} /\left(\mathrm{m}^{2} \mathrm{~K}\right)$. 
Summary of data to be used in the calculation is presented in Table 1. Example values of the internal heat capacity of the building $C_{m}$ are calculated for building space available in the GUS [17] for medium-sized heating system occurring in Poland. It should be noted that for each of heating system should be used current and real data of buildings connected to the district heating network.

Table 1. Data used to calculate the internal heat capacity of buildings.

\begin{tabular}{|c|c|c|c|}
\hline \multirow{2}{*}{$\begin{array}{c}\text { Building } \\
\text { structure }\end{array}$} & $\begin{array}{c}\text { Internal heat capacity relative to the } \\
\text { surface area of the building element }\end{array}$ & $\begin{array}{c}\text { Heated } \\
\text { surface }\end{array}$ & $\begin{array}{c}\text { Internal heat capacity } \\
\text { of building }\end{array}$ \\
\cline { 2 - 4 } & $\boldsymbol{K}_{\boldsymbol{j}}, \mathbf{J} /\left(\mathbf{m}^{\mathbf{2}} \mathbf{K}\right)$ & $\boldsymbol{A}_{\boldsymbol{f}}, \mathbf{m}^{\mathbf{2}}$ & $\boldsymbol{C}_{\boldsymbol{m}}, \mathbf{M J} / \mathbf{K}$ \\
\hline Very light & 80000 & - & - \\
\hline Light & 110000 & - & - \\
\hline Average & 165000 & 26737 & 4411.6 \\
\hline Heavy & 260000 & 85151 & 22139.3 \\
\hline Very heavy & 370000 & 389481 & 144107.0 \\
\hline
\end{tabular}

Compensation time of source thermal power reduction using the heat accumulated in the buildings can be calculated from equation (5):

$$
\tau_{K, b}=Q_{A, b} /\left(3600 \Delta Q_{s r}\right), h
$$

where:

$Q_{A, b}$ - amount of heat accumulated in buildings, MJ,

$\Delta Q_{s r}$ - assumption in reduction of heat source power, MW.

For such presented method of determining the thermal power demand of buildings connected to the district heating system with usage of heat accumulation can be represented graphically compensation times as a function of assumed reducing thermal power of heat source, both for the case of using the thermal storage capacity of district heating network and internal heat capacity of buildings. Example of graphical presentation constructed on the basis of equations 2 and 5 is shown in Fig. 1.

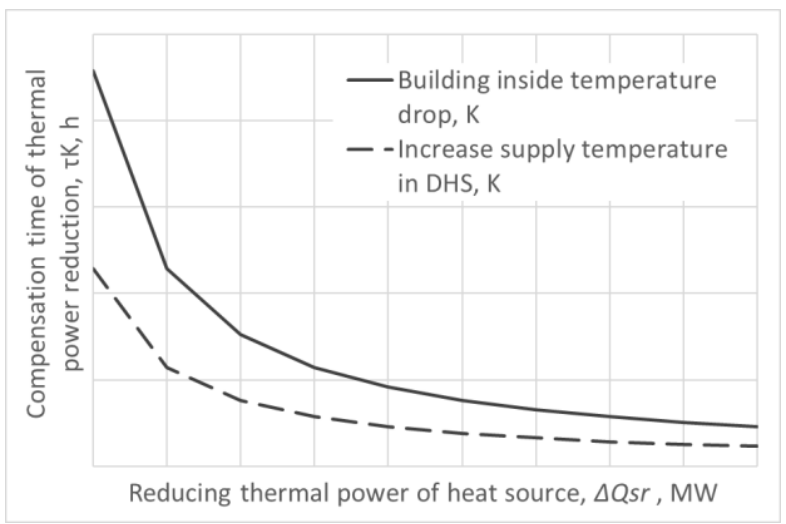

Fig. 1. Example of graphical presentation compensation times as a function of assumed reducing thermal power of heat source. 


\section{Discussion}

The forecast of outside temperature distribution shows a strong correlation in determining the minimum outdoor temperature on the assumed length of the time series. Taking into consideration the value of coefficient of determination $\mathrm{R}^{2}$ below 0.8 obtained results may not be sufficient to provide more accurately calculation the outdoor temperature for the forecast period.

In that case, an analysis of the outside temperature distribution should be conducted, from as long as possible measurement period.

After determining episodes of temporary occurrence of the minimum values of the outside air temperature usually it turns out that one-day episodes statistically one can assume at $1-2$ times per season for average daily outside air temperatures below $-15^{\circ} \mathrm{C}$, and the average daily outside air temperature below $-20^{\circ} \mathrm{C}$ there are only once every four heating seasons. Considering the occurrence of episodes of multi-days occurs that they appear very rarely, and among them may be relevant episodes two- and three-days.

\section{Conclusions}

On the basis of presented determining the thermal power demand of buildings connected to the district heating system with usage of heat accumulation can draw following conclusions:

Having regard to the incidence of outside air temperatures, and the frequency and duration of episodes with the lowest values of outside air temperature the most possible source thermal power reduction for the purpose of central heating is $5-10 \%$.

In addition, taking into account the utilization of the thermal storage capacity of district heating network and internal heat capacity of buildings it is possible to balance the heat power reduction for another $5-10 \%$ in a maximum period of 72 hours. These values are dependent on the permissible temperature increase in the supply of district heating and building inside temperature drop.

It is known that the heating power of district heating system sources in Poland is oversized. It is also evident that the adaptation of the power of heating sources to the building's energy needs will be beneficial for improving the energy efficiency of the district heating system, reducing transmission losses and reducing pollutant emissions. All this leads to maintaining the profitability of heating companies. The presented method does not exhaust the possibilities of usage of heating accumulation of the system, especially with additional heat accumulators. Therefore, it should be carried out further research into the use of alternative methods of determining the thermal power demand of buildings connected to the district heating system with usage of heat accumulation of the system.

The material has been prepared in terms of Czestochowa University of Technology statutory research BS/PB-407-302/11 'Energy-efficient and environmentally sustainable supply systems of buildings in heat, coldness and electricity'.

\section{References}

1. K. Wojdyga, M. Chorzelski, E. Rozycka-Wronska, J. of Clean Prod. 75, 157-165 (2014)

2. H. Lund, S. Werner, R. Wiltshire, S. Svendsen, J. Thorsen, F. Hvelplund, B. Mathiesen, Energy 68, 1-11 (2014)

3. M. Turski, R. Sekret, Rynek Energii 119, 27-34 (2015) 
4. M. Turski, R. Sekret, Rynek Energii 122, 66-74 (2016)

5. K. Wojdyga, Energy and Build. 40, 2009-2014 (2008)

6. M. Santamouris, C. Cartalis, A. Synnefa, D. Kolokotsa, Energy and Build. 98, 119-124 (2015)

7. M. Turski, R. Sekret, J. of Power Technol. 96, 444-448 (2016)

8. A. Colmenar-Santos, E. Rosales-Asensio, D. Borge-Diez, F. Mur-Pérez, Energy 85, 403-414 (2015)

9. P. Späth, H. Rohracher, Energy Policy 78, 273-280 (2015)

10. K. Wojdyga, Renew. Energy 34, 2935-2939 (2009)

11. J. Heier, C. Bales, V. Martin, Renew. and Sustainable Energy Rev. 42, 1305-1325 (2015)

12. K. Wojdyga, Int. J. of Energy and Power Eng. 5, 237-244 (2014)

13. K. Klajic, D. Gvozdenac, S. Vukmirović, Energy 45, 304-311 (2012)

14. P. Piotrowski, Przegląd Elektrotechniczny 90, 1-4 (2014)

15. E. Musiał, E. Gąsiorek, M. Rojek, Acta Agrophysic 3, 333-342 (2004)

16. J. Kajewska, M. Rojek, Water-Environment-Rural Areas 36, 149-160 (2011)

17. I. Adamczyk, K. Andrusiuk, A. Dec, E. Knyszewska, M. Przybylska, B. Różańska, M. Sobczyk, INHABITED BUILDINGS National Census of Population and Housing 2011. Główny Urząd Statystyczny, Departament Handlu i Usług, Warszawa (2013) 